\title{
Kinetics of the adsorption of bovine serum albumin contained in a model wine solution by non-swelling ion-exchange resins
}

\author{
M.R. Sarmento ${ }^{\text {a }}$, J.C. Oliveira ${ }^{b, *}$, M. Slatner ${ }^{c}$, R.B. Boulton ${ }^{\mathrm{d}}$ \\ ${ }^{a}$ Escola Superior de Biotecnologia, UCP, R. Dr. António B. Almeida, Porto, Portugal \\ ${ }^{\mathrm{b}}$ Inter-University Institute of Macau, NAPE, Lot 18, Rua de Londres, Edf. Tak Ip \#P, Macau \\ ${ }^{\mathrm{c}}$ Universitat fur Bodenkultur, Vienna, Austria \\ ${ }^{\mathrm{d}}$ Department of Viticulture and Enology, University of California, Davis CA 95616, USA
}

\begin{abstract}
Adsorption of wine proteins is an essential step in the production of white and rosé wines. In order to develop environmentally friendly adsorption processes, non-swelling adsorbents are required. The performance of selected non-swelling ion-exchange resins (Macro-Prep $^{T M}$ 50S and Streamline ${ }^{\circledR}$ SP) was studied by describing the process kinetics of the adsorption of BSA in a model wine solution. The process was assumed to be diffusion controlled and a shrinking core model was applied. Experiments were performed in the $5-35^{\circ} \mathrm{C}$ temperature range and with different equilibrium partition coefficients. The results obtained with the shrinking core model were theoretically consistent and the apparent diffusivity values correlated very well with theoretically estimated effective diffusivities combined with a linear dependence of porosity with temperature. Separating the temperature effect on porosity, the apparent diffusivity followed an Arrhenius type dependency with temperature with $16.9 \mathrm{~kJ} / \mathrm{mole}$ activation energy.
\end{abstract}

Keywords: Diffusion; Mass transfer; Protein adsorption; Wine stability

\section{Introduction}

The removal of proteins from young white and rosé wines is an essential step in the production of most quality products. This is achieved by immersion of an adsorbing agent, invariably sodium bentonite, a material that swells significantly during the process. This operation causes a significant amount of potentially harmful effluents (resulting from the subsequent filtration with diatomaceous earth) and is also responsible for significant losses (around 10\%, according to local winery data). In order to identify alternative non-swelling materials that could be used to develop environmentally friendly and efficient processes, it is necessary to describe the adsorption kinetics adequately.

In relation to bentonite, the equilibrium is reached in less than $30 \mathrm{~s}$ (Blade \& Boulton, 1988), which implies that the resistance to protein mass transfer to the active sites is negligible, indicating that the active sites are al-

\footnotetext{
${ }^{*}$ Corresponding author. Present address: SPI, Edf. Les Palaces, Rua Julio Diniz, 242-S.208, 4050 Porto, Portugal. Tel.: 351-2-6099152; fax: 351-2-6099164; e-mail: spi@mail.telepac.pt
}

most immediately exposed to the bulk solution with the swelling.

This is not expected in non-swelling adsorbents. The adsorption of a molecule in an active site within a solid matrix involves three possible steps: The movement from the bulk of the fluid to the particle surface (that can be considered equivalent to diffusion through a stagnant layer surrounding the particle), the movement inside the particle to the active site (usually considered diffusional) and the adsorption reaction. Assuming that the exchanging ions are not consumed by accompanying chemical reactions, Helfferich (1965) considered the process to be diffusion controlled, which is to be expected, since usually chemical reactions are faster than diffusion.

It has been reported that film diffusion tends to be the rate limiting step in high porosity adsorbers, when the concentration of active sites is low, or when the particles are significantly small. Internal diffusion tends to be the rate controlling step when diffusing molecules are large compared to the pore size of the adsorbents (Carleysmith, Eanes \& Lilly, 1980; Gopala Rao \& Gupta, 1982; Tsou \& Graham, 1985; Graham, Pucciani \& Pinto, 1987; Pinto \& Graham, 1987; Zhao \& Xingyan, 1990). 
This is normally the case when dealing with protein adsorption, even in macroporous resins. This conclusion, however, applies to individual particles; external resistance can increase significantly in packed beds.

Mathematical modelling of protein diffusion in porous and macroporous supports has been the subject of extensive research. Two models are widely applied: Fickian diffusion and the shrinking core model (SC).

In Fickian diffusion, diffusivity may eventually be time dependent (Tsou \& Graham, 1985; Graham et al., 1987). This model considers that the diffusion takes place homogeneously throughout the matrix, leading to a smooth concentration profile that evolves with time.

The shrinking core (SC) model described by Levenspiel (1972) for fluid-to-particle chemical reactions, was later applied by several researchers to describe the adsorption of protein into porous adsorbents (Carleysmith et al., 1980; Gopala Rao \& Gupta, 1982; Pinto \& Graham, 1987). This model considers that as soon as a molecule reaches an active site, it is adsorbed by the matrix. As a result, the outer layer of the adsorbent saturates fast and the molecules will then have to diffuse through a saturated layer to reach the inner active sites. The particle is thus divided into a saturated layer and a clean core, with the saturation boundary evolving from $R$ to 0 with time.

In the case of this study, the adsorbent particles will be immersed in a solution of limited volume and the process is monitored by determining the evolution of the BSA concentration in the solution. Considering that the equilibrium between the concentrations in the solution and in the particle for these systems is described by a Langmuir-type adsorption isotherm, this implies that the partition coefficient varies with time. In this case, there is no analytical solution of Fick's second law and a Fickian diffusion model would require a numerical solution. Carleysmith et al. (1980) found visual evidence of the existence of a shrinking core in the adsorption of BSA and Penicillin acylase by Amberlite XAD7, using a staining technique. Given these facts, it was decided to test whether the shrinking core model could be applied to the systems under study.

Considering a normal diffusion process through the saturated layer, characterised by a constant diffusivity, $D$, and that the concentration in the bulk solution varies with time (finite volume) but that external resistance is negligible, the result can be written as a linear model response (Gopala Rao \& Gupta, 1982).

$$
\begin{aligned}
F(t) & =\left[1-3\left(1-\frac{C_{\mathrm{p}}}{C_{\mathrm{p}}^{\infty}}\right)^{2 / 3}+2\left(1-\frac{C_{\mathrm{p}}}{C_{\mathrm{p}}^{\infty}}\right)\right] \\
& =\frac{6 D}{\rho_{\mathrm{p}} C_{\mathrm{p}}^{\infty} R^{2}} \int_{0}^{t} C_{\mathrm{b}} \mathrm{d} t,
\end{aligned}
$$

where $C_{\mathrm{b}}$ is the protein concentration (in $\mathrm{mg}_{\text {protein }} / \mathrm{l}$ ) in the bulk solution at time $t, \rho_{\mathrm{p}}$ the specific gravity of the adsorbent, $C_{\mathrm{p}}$ the concentration in the adsorbent particles (in $\mathrm{mg}_{\text {protein }} / \mathrm{mg}_{\text {adsorbent }}$ ) at time $t$ and $C_{\mathrm{p}}^{\infty}$ the concentration in the particle in equilibrium with $C_{\mathrm{b}}$. This form of the model assumes that $C_{\mathrm{p}}^{\infty}$ is constant, which is the case for Langmuir-type isotherms when the range of concentrations in the solution $\left(C_{\mathrm{b}}\right)$ is beyond the corresponding $C_{\mathrm{p}}^{\infty}$ point of maximum adsorption capacity, according to the Langmuir adsorption isotherm. The fact that Eq. (1) can be written as a linear response allows for a simple diagnosis of the adequacy of the model to describe the adsorption process.

The objective of this work was to analyse the internal diffusion process of a protein in selected adsorbents, at conditions found in wine processing, covering a range of values of temperature, equilibrium partition coefficients and concentrations. The results will indicate the applicability of a simple phenomenological model for the engineering design of a continuous or semi-continuous adsorption process for removal of wine proteins.

\section{Materials and methods}

\subsection{Adsorbents}

Two non-swelling adsorbents were chosen: MacroPrep $^{\text {TM }}$ 50S (Biorad laboratories, USA) and Streamline ${ }^{\circledR}$ SP (Pharmacia BioProcess Tech. AB, Sweden) (BioProcess Technology, 1993), because in preliminary work they have shown adequate adsorption characteristics for wine protein removal purposes, both showing Langmuir type isotherms. It can be noted that Macro-Prep is unsuitable to be used in fluidised beds, mainly due to its small particle size. Table 1 shows the main physical characteristics of these adsorbents indicated by the suppliers. Some data were however determined experimentally. The suppliers indicated that the mean particle sizes may vary with different batches (Bio-Rad, 1993). Given the fact that this is an essential parameter for the modelling, one sample was analysed using laser diffraction (Analysette 22, Fritsch GmbH, Oberstein, Germany). The density was determined gravimetrically. The sorption isotherms were determined experimentally at $20^{\circ} \mathrm{C}$ and in the case of Macro-Prep for all temperatures of interest. In all cases, it was found that the maximum adsorption capacity was achieved at $C_{\mathrm{b}}$ around $60 \mathrm{mg} / \mathrm{l}$, which is generally lower than the operating range (see Table 2), validating the assumption that $C_{\mathrm{p}}^{\infty}$ is constant (and equal to $C_{\mathrm{p}}^{\max }$ ).

\subsection{Model wine}

Considering the large diversity of protein fractions found in wines and its variability which is due to a complex combination of several factors, such as climate, soil, cultivar, cultural practices, growth conditions and 
Table 1

Physical properties of the adsorbents studied ${ }^{\mathrm{a}}$

\begin{tabular}{lll}
\hline & Macro-Prep ${ }^{\mathrm{rM}} 50 \mathrm{~S}^{\mathrm{b}}$ & Streamline $^{\circledR} \mathrm{SP}^{\mathrm{c}}$ \\
\hline Matrix structure & Acrylic, macroporous & Macroporous cross-linked agarose, 6\%, with quartz core \\
Particle shape & spherical & $25-100$ \\
Particle size range $(\mu \mathrm{m})^{\mathrm{d}}$ & $35-90$ & 50 \\
Mean diameter $(\mu \mathrm{m})^{\mathrm{d}}$ & 60.2 & 1.20 \\
Density $(\mathrm{g} / \mathrm{ml})^{\mathrm{d}}$ & 1.32 & 1000 \\
Pore size & 1000 & Not available \\
Pore volume $\left(\mathrm{cm}^{3} / \mathrm{g}\right)$ & $0.5-0.7$ & Sulfonic \\
Ionic group & Sulfonic & 0.338 \\
Capacity, $C_{\mathrm{p}}^{\max }(\mathrm{mg} / \mathrm{mg})^{\mathrm{d}}$ & 0.184 & 4.16 \\
Langmuir constant, $K_{L}(\mathrm{mg} /)^{\mathrm{d}}$ & 8.09 & \\
\hline
\end{tabular}

${ }^{a}$ Langmuir equation: $C_{\mathrm{p}}^{\infty}=C_{\mathrm{p}}^{\max } C_{\mathrm{b}} /\left(K_{\mathrm{L}}+C_{\mathrm{b}}\right)$, where $C_{\mathrm{b}}$ is the protein concentration in the solution in equilibrium with $C_{\mathrm{p}}^{\infty}$.

${ }^{\mathrm{b}}$ Bio-Rad, 1993.

${ }^{\mathrm{c}}$ BioProcess Technology, 1993.

d experimentally determined.

processing technologies, a model wine solution was used. This model wine was suggested by Blade and Boulton (1988), having similar physical characteristics to a typical wine that are relevant to protein instability studies. It was prepared with $12 \%(\mathrm{v} / \mathrm{v})$ ethanol and $2 \mathrm{~g} / 1$ of potassium hydrogen tartrate in distilled water. The solution had a final $\mathrm{pH}$ of 3.72. Bovine Serum Albumin (BSA), fraction V (Merck KGaA, Germany), was used as a model protein. BSA has a molecular weight of 66 KDalton and an isoelectric point of 4.3 , which are in the range of wine proteins. It is considered to provide conservative estimates regarding wine protein diffusion, because it is larger than most wine proteins (Blade \& Boulton, 1988).

\subsection{Adsorption kinetics}

The adsorption kinetics were determined by immersing the resin in the model wine solution containing BSA, at controlled temperature and high stirring (to minimise external resistance), and measuring BSA concentration in the solution at time intervals by spectrophotometry at $280 \mathrm{~nm}$. Experiments were performed at room temperature $\left(20^{\circ} \mathrm{C}\right)$ for both adsorbents and for Macro-Prep the temperature range of $5-35^{\circ} \mathrm{C}$ was studied by performing several isothermal experiments in that range, which is considered to be representative of typical conditions in winemaking. Analysis of mass transfer processes over a range of temperatures allows

Table 2

Experimental conditions ${ }^{\mathrm{a}}$

\begin{tabular}{|c|c|c|c|c|c|}
\hline Adsorbent & Temperature $\left({ }^{\circ} \mathrm{C}\right)$ & $\begin{array}{l}\text { Mass of adsorbent added } \\
(\mathrm{g} / \mathrm{l})\end{array}$ & $\begin{array}{l}\text { Equilibrium partition } \\
\text { coefficient }\left(\alpha^{\infty}\right)\end{array}$ & $C_{\mathrm{b}}^{0}(\mathrm{mg} / \mathrm{l})$ & $C_{\mathrm{b}}^{\infty}(\mathrm{mg} / \mathrm{l})$ \\
\hline \multirow[t]{15}{*}{ Macro-Prep } & 5 & 1.955 & 0.707 & 500 & 208.6 \\
\hline & & 2.262 & 0.486 & 500 & 164.7 \\
\hline & & 3.066 & 0.088 & 500 & 40.78 \\
\hline & 12.5 & 1.548 & 1.006 & 500 & 251.3 \\
\hline & & 1.719 & 0.7999 & 500 & 222.5 \\
\hline & & 2.150 & 0.4384 & 500 & 152.7 \\
\hline & 20 & 1.019 & 1.681 & 500 & 315.8 \\
\hline & & 1.711 & 0.5867 & 500 & 186.3 \\
\hline & & 2.329 & 0.1704 & 500 & 73.32 \\
\hline & 26 & 0.967 & 1.658 & 500 & 312.7 \\
\hline & & 2.067 & 0.2540 & 500 & 101.4 \\
\hline & & 2.467 & 0.0498 & 500 & 23.91 \\
\hline & 35 & 0.806 & 1.934 & 500 & 331.6 \\
\hline & & 0.906 & 1.656 & 500 & 319.8 \\
\hline & & 1.001 & 1.450 & 500 & 309.5 \\
\hline \multirow[t]{3}{*}{ Streamline } & 20 & 0.328 & 3.603 & 500 & 391.4 \\
\hline & & 0.592 & 1.545 & 500 & 303.5 \\
\hline & & 0.792 & 0.8970 & 500 & 236.4 \\
\hline
\end{tabular}

${ }^{\mathrm{a}} C_{\mathrm{b}}^{0}$ and $C_{\mathrm{b}}^{\infty}$ are the protein concentrations in the solution at time zero and at equilibrium, respectively. 
for a better insight into the process, as the results of this work will also show. The temperatures used were $5^{\circ} \mathrm{C}$, $12.5^{\circ} \mathrm{C}, 20^{\circ} \mathrm{C}, 26^{\circ} \mathrm{C}$ and $35^{\circ} \mathrm{C}$.

It is also important to analyse if there is a concentration dependence of the diffusivity. For this purpose, different amounts of adsorbents were used, for the same initial concentration of protein in the solution. The higher the amount of adsorbent, the higher the range of concentrations covered by the experiment. The amounts added, at each temperature, corresponded to different partition coefficients (ratios of the mass of protein in the liquid to that in the solids at equilibrium: $\alpha^{\infty}=m_{\mathrm{b}}^{\infty} / m_{\mathrm{p}}^{\infty}$ ). Table 2 summarises the experimental conditions used.

The resins were initially dried at room temperature, weighed and hydrated with $150 \mathrm{ml}$ of model solution, for about $2 \mathrm{~h}$. At time zero, $150 \mathrm{ml}$ of BSA in model wine were then added to the hydrated beads.

The solution was pendular-agitated in Earl-Meyer flasks, as regular stirrers were observed to damage the beads. A magnetic stirrer (Multipoint HP15, Variomag submersible stirrers, $\mathrm{H}+\mathrm{P}$ Labortechnik $\mathrm{GmbH}$, Germany) was immersed in a controlled temperature water bath. For temperatures lower than ambient, where refrigeration was needed, a 'cold finger' was used and the temperature was controlled by the thermostat of the isothermal bath.

The system used is described in Fig. 1. The solution was separated from the adsorbent, by operating a peristaltic pump and filtering through a $2 \mu \mathrm{m}$ filter (Millipore, USA). This filter was fitted inside a special housing, so that the area of the filter was in direct contact with the solution. Protein concentration was measured by spectrophotometry at $280 \mathrm{~nm}$ (Unicam $8620 \mathrm{UV} / \mathrm{V}$ is spectrometer, Phillips, Eindhoven, Holland) against a blank solution (without BSA).

The use of a system for continuous readings was not possible. Air that was continuously dissolved in the solution, due to stirring, tended to remain trapped in the

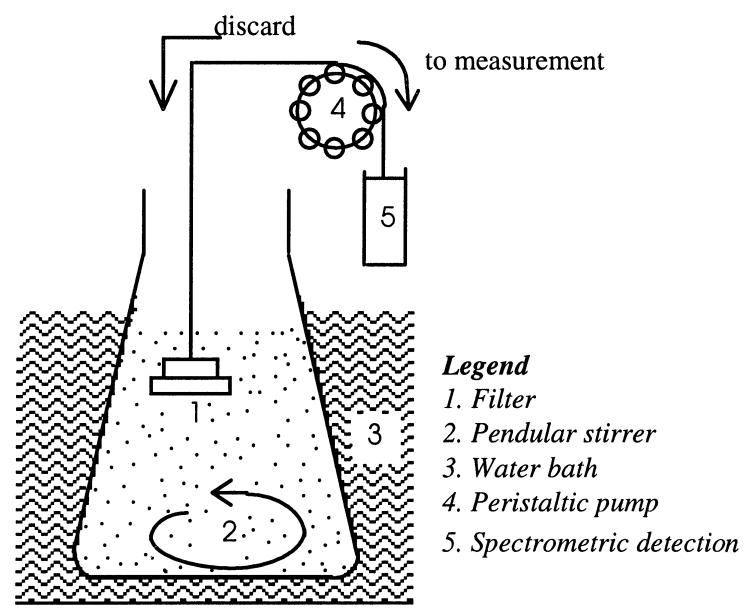

Fig. 1. Scheme of the system used to determine the kinetics of BSA adsorption. spectrophotometer flow cell, resulting in highly erratic readings. A more difficult problem was that the adsorbent beads formed a cake in the filter, due to the continuous pumping of the solution. This cake would act as a packed bed of adsorbent, and the assumption of negligible external resistance would not be fully satisfied. Therefore, discrete samples were taken at short time intervals only. After readings, the solution inside the tubes was returned to the adsorption flask, by inverting the direction of the flow in the pump. Because the sampling time was short, the formation of the cake was negligible during each sampling. By reversing the flow, the small amount of adsorbent beads that were pushed to the filter were released back to the solution, therefore minimising this problem.

The equilibrium concentration was determined experimentally by monitoring the adsorption process until the difference between two readings with $3 \mathrm{~h}$ intervals was lower than the spectrophotometer absolute error (0.003 AU).

\section{Results and discussion}

\subsection{Shrinking core model results}

The experimental data were fitted by Eq. (1), calculating $\int_{0}^{t} C_{\mathrm{b}} \mathrm{d} t$ numerically with Simpson's rule for each experimental point. Fig. 2 shows the plots at $20^{\circ} \mathrm{C}$, where it can be seen that the model is quite good. In all other cases, similar straight lines with zero intercept were obtained, with correlation coefficients above 0.99 .

Fig. 3 shows the values of the apparent diffusivity calculated with this model as a function of the equilibrium partition coefficient. It can be seen that the partition coefficient does not affect the results significantly. This supports the hypothesis that diffusivity is not concentration dependent, as required by the model. An overall diffusion coefficient for each temperature was determined by fitting the respective set of three experiments jointly, treating them subsequently as replicates.

A further diagnosis of the model adequacy is provided by the correlation of the model predictions with the experimental data (Fig. 4).

\subsection{Influence of temperature on the apparent diffusivity}

The dependency of diffusivity on temperature was studied for Macro-Prep. Results are shown in Fig. 5, where an Arrhenius type behaviour can be seen. The activation energy obtained was $37.6 \mathrm{~kJ} / \mathrm{mole}$. This value is slightly higher than normal values of diffusional processes in porous media and foods, which are mostly in the range of 15-35 kJ/mole (Levenspiel, 1972; Moreira, Silva, Oliveira \& Oliveira, 1993), indicating a higher influence of temperature than what should be expected 


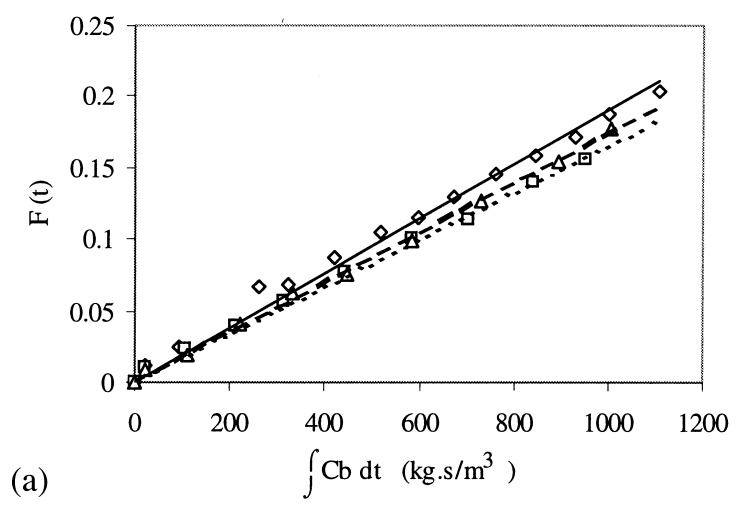

(a)

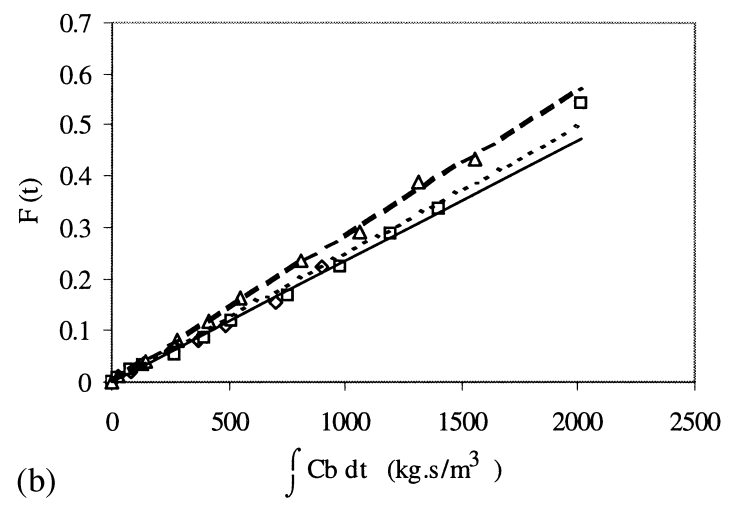

Fig. 2. Analysis of the shrinking core model response at $20^{\circ} \mathrm{C}$. (a) Macro-Prep $\left(\diamond \alpha^{\infty}=0.170, \square \alpha^{\infty}=0.59 ; \Delta \alpha^{\infty}=1.7\right)$; (b) Streamline $\left(\diamond \alpha^{\infty}=0.897, \square \alpha^{\infty}=1.55 ; \Delta \alpha^{\infty}=3.60\right)$.

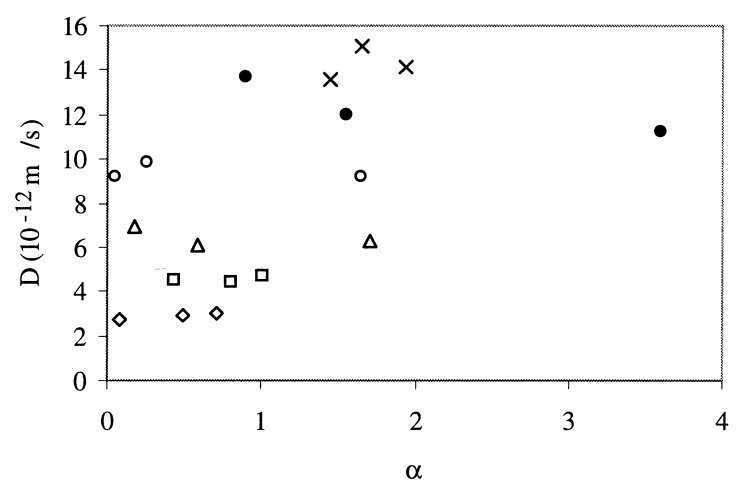

Fig. 3. Apparent BSA diffusivities in Macro-Prep $\left(\diamond 5^{\circ} \mathrm{C}, \square 12^{\circ} \mathrm{C} ; \Delta\right.$ $\left.12.5^{\circ} \mathrm{C} ; \bigcirc 26^{\circ} \mathrm{C} ; \times 35^{\circ} \mathrm{C}\right)$ and Streamline $\left(\bullet 20^{\circ} \mathrm{C}\right)$.

of a diffusional process. There may be therefore some other effect that is influencing the results and that must be separated.

The resin maximum capacity at each temperature was determined experimentally in the same experiments, by letting the adsorption proceed to equilibrium. It was found that this equilibrium concentration varied linearly with temperature, as shown in Fig. 6. The amount of protein molecules that are adsorbed by interaction with the exchange groups in a porous solid matrix of sizes with similar order of magnitude to those of the mole-

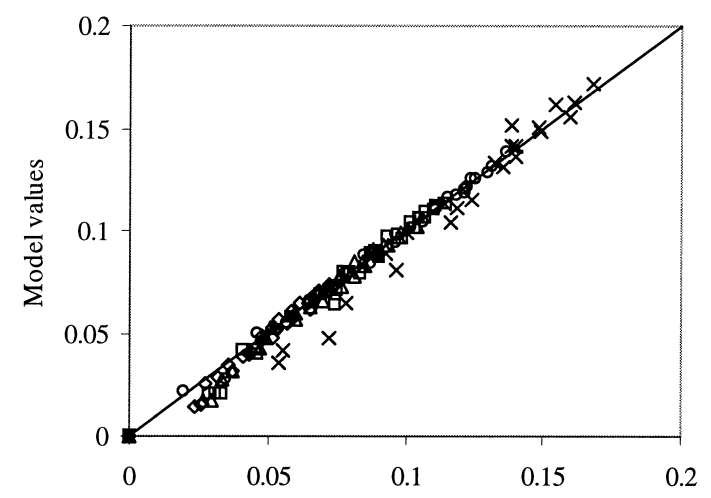

(a)

Experimental concentration

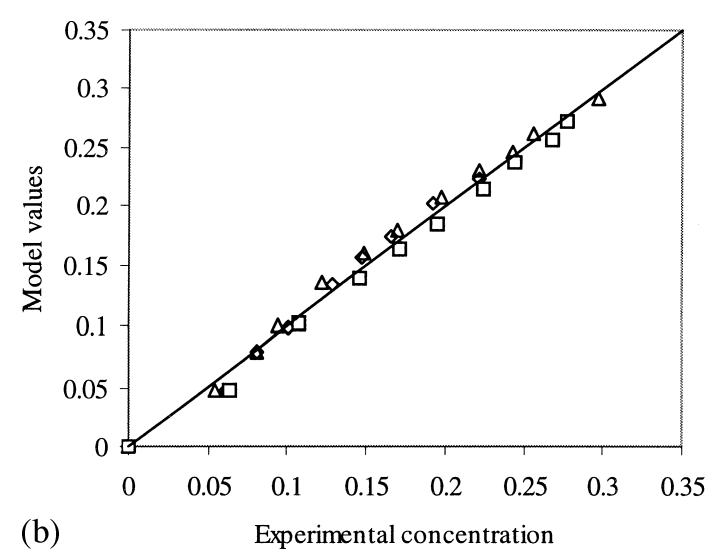

Fig. 4. Diagnosis plot of the shrinking core model fits. (a) Macro-Prep $\left(\diamond 5^{\circ} \mathrm{C}, \square 12^{\circ} \mathrm{C} ; \Delta 12.5^{\circ} \mathrm{C} ; \bigcirc 26^{\circ} \mathrm{C} ; \times 35^{\circ} \mathrm{C}\right)$; (b) Streamline $(\diamond$ $\alpha^{\infty}=0.897, \square \alpha^{\infty}=1.55 ; \Delta \alpha^{\infty}=3.60$ ).

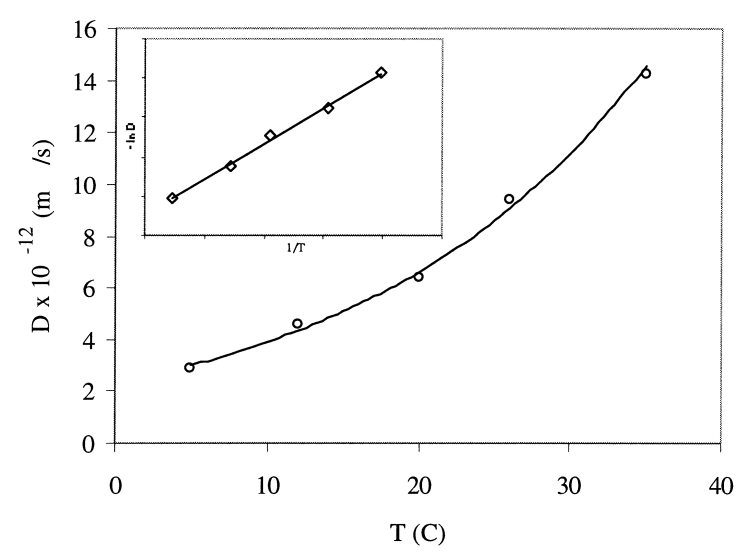

Fig. 5. Influence of temperature on the apparent diffusivity of BSA in Macro-Prep. The Arrhenius plot is on the top left corner.

cules themselves is limited by the volume of the pores (Terence, 1990). Therefore the increase of the capacity may be due to an increase of the porosity, as a result of the expansion of the resin matrix with increasing temperature, or to conformational changes of the protein molecules with temperature. If porosity increases with temperature, then the apparent diffusivity will show a 


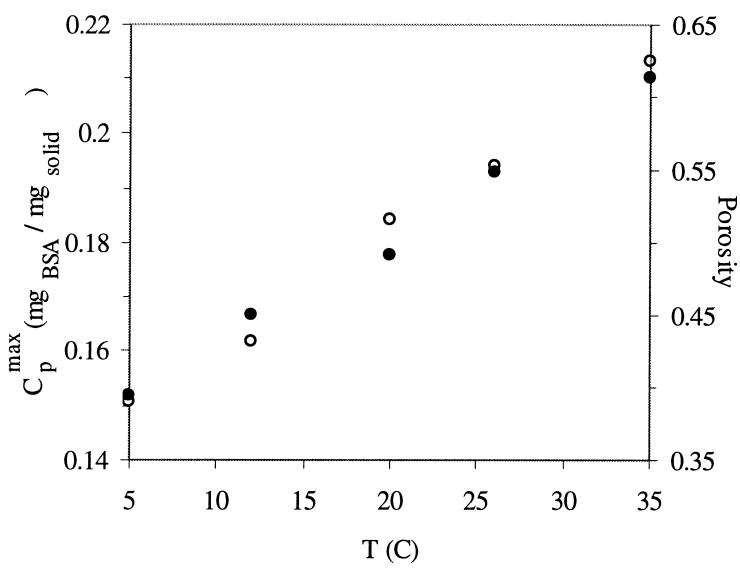

Fig. 6. Influence of temperature on the experimental maximum adsorption capacity $(\bigcirc$, left axis) and on the estimated porosity $(\bullet$, right axis).

higher influence of temperature than expected and the effect of porosity must be separated. Porosity can be estimated by calculating theoretically the expected effective diffusivity and obtaining the porosity by comparison with the experimental data.

\subsection{Effective diffusivity}

Mackie and Meares (1955) proposed an empirical correlation to estimate the apparent diffusivity as a function of the effective diffusivity and of porosity (that is, neglecting the effect of turtuosity) that was applied by Pinto and Graham (1987) for protein adsorption

$D=D_{\mathrm{e}}\left(\frac{\varepsilon}{2-\varepsilon}\right)^{2}$,

where $\varepsilon$ is the particle porosity and $D_{\mathrm{e}}$ the effective diffusivity (diffusivity of the protein in a free solution). The effective diffusivity can be estimated from the protein molecular weight, assuming an average protein partial specific volume of $0.73 \mathrm{~cm}^{3} / \mathrm{g}$, by using the correlation proposed by Young, Carroad and Bell (1980) for diffusion of proteins

$D_{\mathrm{e}}=100 \exp \left(\frac{-8 T_{\mathrm{k}}}{\mu \mathrm{MW}^{1 / 3}}\right)$,

where $T_{\mathrm{k}}$ is the absolute temperature $(K), \mathrm{MW}$ is the molecular weight $(\mathrm{kg})$ and $\mu$ is the viscosity (in centipoise), that can in turn be predicted for the model wine solution from the viscosity of the different components according to the correlation suggested by Reid, Prausnitz and Sherwood (1977)

$\ln \left(\mu_{\text {mixture }}\right)=\sum_{i=1}^{n_{c}} \chi_{i} \ln \left(\mu_{i}\right)$,

where $\chi_{i}$ is the molar fraction of component $i$ and $n_{\mathrm{c}}$ the total number of components of the solution (only water and ethanol were considered, neglecting the effect of potassium hydrogen tartrate). The variation of the viscosity with temperature for each pure component can be estimated using an Antoine-type empirical equation (Reid et al., 1977)

$\log \mu_{i}=A^{\prime}+\frac{B^{\prime}}{T-T^{\prime}}$.

The three parameters $A^{\prime}, B^{\prime}$ and $T^{\prime}$ are given in the literature for a large number of liquids and liquid mixtures (Reid et al., 1977). With $T$ in Kelvin and $\mu$ in centipoise, for water $A^{\prime}=-2.442, B^{\prime}=774.4, T^{\prime}=$ -15.25 and for ethanol $A^{\prime}=-1.567, B^{\prime}=230.3$, $T^{\prime}=-146.8$.

It is therefore possible to estimate the effective diffusivity by combining Eq. (3)-(5), simply from the solution composition and the protein molecular weight. Fitting these values with the experimental apparent diffusivity, $D$, to Eq. (3) one can estimate the values of porosity. Fig. 6 shows the results obtained, where it can be seen that a very similar type of dependency was found to that obtained for the resin maximum capacity. Furthermore, the results are well within reasonable values given by the supplier (see Table 1).

Applying the same correlation to Streamline yields a porosity at $20^{\circ} \mathrm{C}$ of 0.62 , which again is a reasonable value. The higher porosity of Streamline may be associated to the higher diffusivity and higher maximum adsorption capacity shown by this resin.

The results with Macro-Prep indicate that the observation that the influence of temperature on the apparent diffusivity was higher than expected was due to the effect of temperature on the porosity. The data obtained for the porosity dependence on temperature were well correlated by an Arrhenius type equation, with an activation energy of $10.3 \mathrm{~kJ} / \mathrm{mole}$. The effective diffusivities calculated with Eq. (3) can also be adjusted by an Arrhenius model (see Fig. 7), with an activation energy of $16.9 \mathrm{~kJ} / \mathrm{mol}$, a value which is more in agreement with diffusional processes.

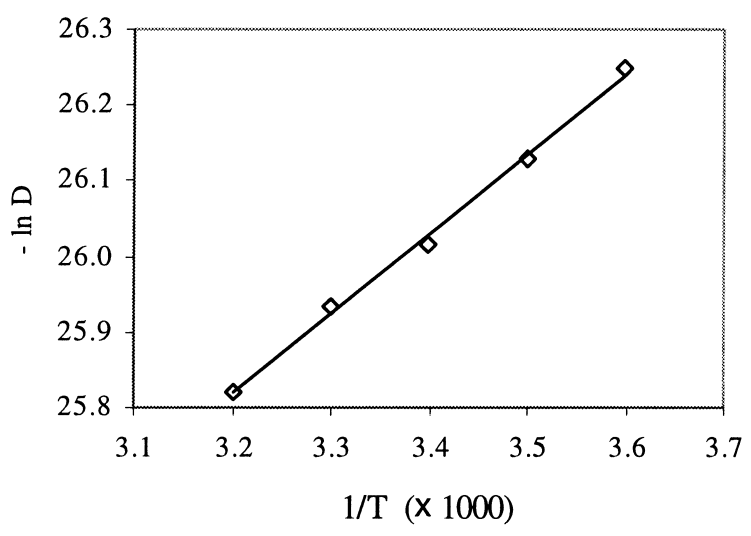

Fig. 7. Arrhenius plot of the effective diffusivity of BSA. 


\section{Conclusions}

The adsorption of BSA contained in a model wine solution into macroporous adsorbents represented by two ion-exchange resins was controlled by intraparticle diffusion and well described by the shrinking core model.

The analysis of the influence of temperature on the apparent diffusivity for Macro-Prep 50S, allowed to conclude that the resin maximum capacity increases with temperature in a way that is very well correlated with an increase in the porosity. The application of empirical correlations to estimate the effective diffusivity coupled with the empirical relation between temperature and porosity found, yielded very good estimates, that required only the protein molecular weight and the composition of the solution. Streamline showed a higher porosity, maximum adsorption capacity and diffusivity, which may be related factors, although the pore sizes indicated by both suppliers were equal.

In relation to extrapolation to real wine systems, it must be noticed that protein-protein interactions are likely to be significant.

\section{Acknowledgements}

The authors are grateful to the Luso-American Foundation for Development (FLAD) for financial support. Author Sarmento would also like to acknowledge JNICT (Junta National de Investigação Científica e Tecnológica, Portugal) for financial support.

\section{References}

BioProcess Technology (1993). StreamLine ${ }^{\circledR}$ adsorbents. Technical information bulletin, BioProcess Technology AB: Uppsala, Sweden.
Bio-Rad (1993). A Technical Investigation of Macro-Prep ${ }^{\text {TM }}$ Chromatography Supports, Bio-Rad laboratories: Hercules, USA.

Blade, W. H., \& Boulton, R. (1988). Adsorption of protein by bentonite in a model wine solution. American Journal of Enology and Viticulture, 39, 193-199.

Carleysmith, S. W., Eanes, M. B. L., \& Lilly, M. D. (1980). Staining method for determination of the penetration of immobilised enzyme into a porous support. Biotechnology and Bioengineering, 22, 957-967.

Gopala Rao, M., \& Gupta, A. K. (1982). Kinetics of ion exchanges in weak-base anion exchange resins. AIChE Symposium Series, 78, 96-102.

Graham, E. E., Pucciani, A., \& Pinto, N. (1987). A comparative study of models to predict protein adsorption. Biotechnology Progress, 3(3), 141-145.

Helfferich, F. (1965). Ion-exchange kinetics. V-ion exchange accompanied by reactions. Journal of Physical Chemistry, 69(4), 11781187.

Levenspiel, O. (1972). Chemical Reaction Engineering, New York: John Wiley and Sons.

Mackie, J. S., \& Meares, P. (1955). The diffusion of electrolytes in a cation-exchange resin membrane. Proceedings of the Royal Society, A232, 498-503.

Moreira, L., Silva, T. P., Oliveira, J. C., \& Oliveira, F. A. R. (1993). Development of a non-isothermal method for determination of diffusional parameters. International Journal of Food Science and Technology, 28, 575-586.

Pinto, N. G., \& Graham, E. E. (1987). Application of the shrinkingcore model for predicting protein adsorption. Reactive polymers, 5 , 49-53.

Reid, R. C., Prausnitz, J. M., \& Sherwood, T. K. (1977). The properties of gases and liquids, 3d ed., New York: Mc Graw-Hill.

Terence, A. (1990). Particle size measurement, 4th ed., New York: Chapman and Hall.

Tsou, H. S., \& Graham, E. E. (1985). Prediction of adsorption and desorption of protein on Dextran based ion-exchange resin. AIChE Journal, 31(12), 1959-1960.

Young, M. E., Carroad, P. A., \& Bell, R. L. (1980). Estimation of diffusion coefficients of proteins. Biotechnology and Bioengineering, 22, 947-955.

Zhao, F., \& Xingyan, W. (1990). Statics and kinetics of sorption of streptomycin on macroporous weak-base ion exchange resin D302x6. Reactive polymers, 13, 93-101. 